\title{
Age and growth of two bream species in the Tudakul reservoir of Uzbekistan
}

\author{
$B$. Kamilov ${ }^{1, *}, M$. Yuldashov ${ }^{1}, R$. Khakimova ${ }^{1}$, and $M$. Ibodova $^{2}$ \\ ${ }^{1}$ Tashkent State Agrarian University, University str., 2, Tashkent province, Uzbekistan, 100140 \\ ${ }^{2}$ Navoi State Pedagogical Institute, Ibn Sino str., 45, Navoi, Uzbekistan, 210100
}

\begin{abstract}
The study was carried out in 2014-2018 at the Tudakul reservoir, Uzbekistan. Samples included 278 European bream (Abramis brama), and 83 Amur white bream (Parabramis pekinensis). The age, total length and weight of the fish varied from 1 to 5 years, from 14 to $50 \mathrm{~cm}$, from 30 to $1,405 \mathrm{~g}$ for the European bream and from 1 to 6 years, from 24 to $53.5 \mathrm{~cm}$ and $105-2,138 \mathrm{~g}$ for the white Amur bream and European bream, respectively. The relationship between total length (TL) and weight (W) is described by the equation $\mathrm{W}=0.005 * \mathrm{TL}^{3.2555}(\mathrm{r}=0.98)$ for European bream and $\mathrm{W}=0.005 * \mathrm{TL}^{3.201}(\mathrm{r}=0.96)$ for white Amur bream. Recovered average growth rate of European bream: TL1 - $13.5 \mathrm{~cm}$; TL2 $28.1 \mathrm{~cm}$, TL3 - $37.95 \mathrm{~cm}$, TL4 - $42.6 \mathrm{~cm}$, TL5 - $48.6 \mathrm{~cm}$. The average height of the Amur white bream: TL1 - $12.6 \mathrm{~cm}$, TL2 - $23.3 \mathrm{~cm}$, TL3 $31.5 \mathrm{~cm}$, TL4 - $37.9 \mathrm{~cm}$, TL5 - $41.7 \mathrm{~cm}$, TL6 - $44.2 \mathrm{~cm}$. Lee's phenomenon did not appear. All yearling fish were juvenile. In 2-year-old fish of both sexes of both species, the gonads were at stage II. Males and females of both species reached their first maturity at 3-4 years of age, when the total body length of the European bream was $30-32 \mathrm{~cm}$, and the Amur white bream was $34-35 \mathrm{~cm}$.
\end{abstract}

\section{Introduction}

Biological invasions are one of the most serious problems that threaten the conservation of biodiversity, including fish resources. The adaptation of the species to new conditions requires research. Often, an introduced species cannot create a new population under new conditions. However, if a species successfully creates a self-reproducing population, then this introduction of the species into a new ecosystem is likely to have a significant impact on the local ecosystem. The adaptation success of an introduced species is highly dependent on its inherent ecological and biological characteristics (for example, reproduction, fertility, dietary diversity) $[1,2,6,7,16]$.

In the basin of the Zarafshan River in Uzbekistan, two types of bream are examples of invasive species - European (common) bream, Abramis brama (Linnaeus, 1758) and Amur white bream Parabramis pekinensis (Basilewsky, 1855) [3].

The range of European bream includes the central and northern part of Europe, the basins of the Caspian, Black, and Azov seas and introduced into the basins of the Ob,

\footnotetext{
*Corresponding author: b.kamilov@tdau.uz
} 
Irtysh, Yenisei (Russia). In the Aral Sea basin, the subspecies A. brama orientalis Berg was identified in the sea and in the lower reaches of the Amu Darya and Syrdarya rivers (Kamilov, 1973). In the 1950s, European bream from the Ural River (Russia) was brought to the Kuyumazar reservoir in the middle reaches of the Zarafshan River basin. The bream found a favorable environment, started natural reproduction and spread in the middle and low streams of the river, including the Tudakul reservoir. Recently, the species has the status of a commercial fishery in all water bodies of the Zarafshon River basin $[4,6]$. In Uzbekistan, the biology of European bream, including growth and maturation, was studied until the 1980s; there have been virtually no studies since the early 1990s [4].

Since 2008, white Amur bream, previously unseen in the ichthyofauna of Uzbekistan, has come across in research fishing in the reservoir. It is known that during the introduction of Chinese cyprinids into the fish farms of Turkmenistan in the early 1960s, this species was unauthorizedly introduced, and this species, which took root, penetrated the irrigation canals and reservoirs of Turkmenistan, gradually penetrated the middle reaches of the Amu Darya, and from there into the Amu-Bukhara machine channel [5, 8]. From 2014-2015, individuals of the white Amur bream began to come across quite often already in the commercial catches in the Tudakul reservoir. There are practically no data on the biology of the species in Uzbekistan [9].

Considering all the above, the aim of this work was to study the age, growth and maturation of European bream and Amur white bream in the Tudakul reservoir.

\section{Materials and methods}

The Tudakul reservoir was created for the annual redistribution of water from the Zarafshan and Amu Darya rivers (in the middle reaches) for the needs of irrigated agriculture. Hydrographically, the reservoir was created in the lower reaches of the Zarafshan (39॰51'15" N 6450'29" E) [10]. Water supply from the Amu Darya is carried out through the Amu-Bukhara machine channel. This is an arid zone with a sharply continental climate: hot summers (the average monthly air temperature in July is about $29^{\circ} \mathrm{C}$, during the day the temperature often exceeds $37-42^{\circ} \mathrm{C}$ ) and rather cold winters (the average monthly air temperature in January is about $-2^{\circ} \mathrm{C}$, lake-type reservoirs can be covered with ice up to 1.5 months). The total area of the reservoir is about 22 thousand hectares, the average depth is about $5 \mathrm{~m}$, and the maximum depth is $22 \mathrm{~m}$. Since 2004, the regime of pasture aquaculture has been used in the reservoir with the stocking of the reservoir with juvenile pond fish and fish fishing mainly by seines with a netting with a large mesh more than $70 \mathrm{~mm}$ ) for catching large fish $[10,11]$.

Fish were caught during research fishing with fixed nets with a mesh of $16-70 \mathrm{~mm}$ in 2014-2018 in the Tudakul reservoir. In the studied fish, the total body length (TL, cm) and the length of the body to the end of the standard length (SL, cm) were measured with an accuracy of $1 \mathrm{~mm}$, the total body weight $(\mathrm{w}, \mathrm{g})$ was measured with an accuracy of $0.1 \mathrm{~g}$. The scales were collected from the middle bodies in the first row above the lateral line strictly under the first ray of the dorsal fin. In laboratory conditions, the scales were cleaned, a preparation was made, by which the age of the fish was determined and the size of the annual rings was measured using an MBS-1 binocular magnifier. Height was determined by inverse calculation according to the Einar Lea formula. The sex and maturity stage of the gonads were determined $[11,12]$.

The relationship between body length and weight was determined by the Ricker formula (Ricker, 1975): $\mathrm{w}=\mathrm{a} * \mathrm{TLb}$, where $\mathrm{w}$ is the total body weight $(\mathrm{g})$, TL is the total body length $(\mathrm{cm})$, "a" and "b" are the coefficients of the equation. 
Gonad samples were fixed in Bouin's solution; Paraffin wax sections 5-7 $\mu \mathrm{m}$ in size were stained with hematoxylin. According to Makeeva [3], ovarian development was divided into six stages.

Correlation and regression analyzes were performed to describe the fertility equations; statistical significance was checked for $\mathrm{p}<0.05$.

\section{Results}

\subsection{European bream}

A total of 278 European bream were selected, including 126 females and 152 males. The ratio of females to males was determined as $1: 1.2$. The age of the fish in the samples ranged from 1 to 5 years, the total length is $14-51 \mathrm{~cm}$, the standard length is $11.5-41.0 \mathrm{~cm}$, and the total body weight is from 30 to $1405 \mathrm{~g}$.

The scales of the European bream are cycloid with smooth edges. The species belongs to large-scaled fish, in our study 49 - 85 scales in the lateral line were identified.

In colder months, sclerites on scales are brought together; in warmer months, sclerites are located far from each other. The annual ring can be identified by the belt of closely related sclerites; we did not reveal other morphological characteristics of the annual ring. Annual rings on scales in immature European bream appear in March, and in sexually mature fish in May.

Sometimes, additional rings on the scales were noted, formed as a result of various events that caused growth arrest during the growing season. Accessory rings are thin, not closed, and not visible on all scales.

The relationship between standard length and total length can be described by the regression equation6 $\mathrm{TL}=1.1967 * \mathrm{SL}+0.9333(\mathrm{r}=0.99)$.

There were no significant differences between the sizes of fish of different sexes in generations; therefore, all calculations were performed for fish of both sexes (female + male). The dependence of total body mass on total length is shown in Figure 1 and can be described by the equation $\mathrm{W}=0.005 * \mathrm{TL}^{3.2555}(\mathrm{r}=0.98)$.

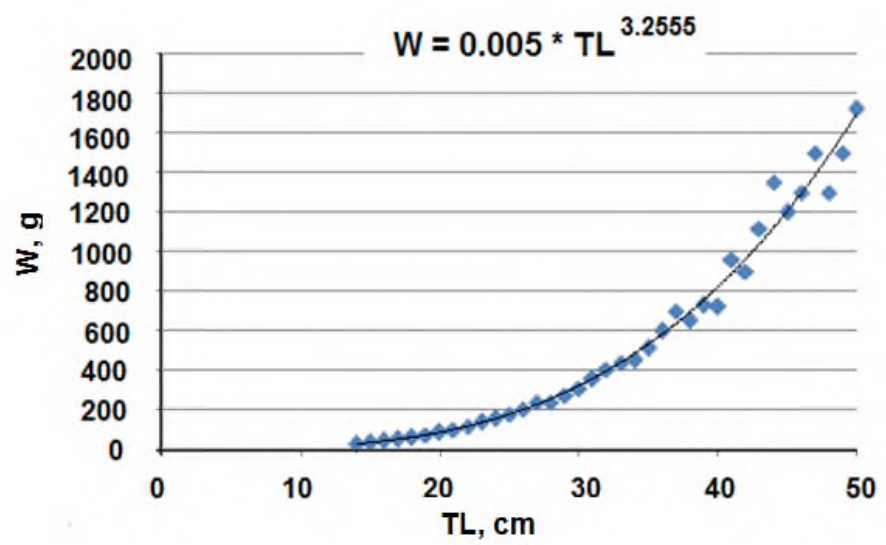

Fig. 1. Dependence of total body weight and total body length in European bream in the Tudakul reservoir, Uzbekistan

The empirical growth of European bream is shown in Table 1. The growth restored by the method of reverse calculation is shown in Table 2. R. Lee's phenomenon did not appear. 
Table 1. Empirical growth of European bream in the Tudakul reservoir (above the line - spread, below the line - average)

\begin{tabular}{|c|c|c|c|c|c|}
\hline \multirow{2}{*}{ Indicator } & \multicolumn{5}{|c|}{ Age, year } \\
\cline { 2 - 6 } & $\mathbf{1}$ & $\mathbf{2}$ & $\mathbf{3}$ & $\mathbf{4}$ & $\mathbf{5}$ \\
\hline \multirow{2}{*}{ Total length (TL), cm } & $\frac{14-32}{22.5}$ & $\frac{21-39}{28.6}$ & $\frac{29-47}{38.9}$ & $\frac{40-45.5}{42.7}$ & $\frac{40-48.5}{47.3}$ \\
\hline \multirow{2}{*}{ Total weight (W), g } & $\frac{30-395}{127.2}$ & $\frac{105-760}{291.7}$ & $\frac{2,985-1,305}{778.4}$ & $\frac{755-1,250}{1,040.1}$ & $\frac{1,140-1,405}{1,315}$ \\
\hline \# of population & 92 & 52 & 108 & 23 & 3 \\
\hline
\end{tabular}

Table 2. Restored growth rate of European bream in the Tudakul reservoir

\begin{tabular}{|c|c|c|c|c|c|c|}
\hline \multirow{2}{*}{$\begin{array}{c}\text { Age group, } \\
\text { year }\end{array}$} & \multirow{2}{*}{$\#$} & \multicolumn{5}{|c|}{$\mathbf{T L}, \mathbf{c m}$} \\
\hline & & $\boldsymbol{T L}_{\boldsymbol{1}}$ & $\boldsymbol{T L}_{\mathbf{2}}$ & $\boldsymbol{T L}_{\boldsymbol{3}}$ & $\boldsymbol{T L}_{\boldsymbol{4}}$ & $\boldsymbol{T L}_{5}$ \\
\hline 1 & 92 & 13.3 & & & & \\
\hline 2 & 52 & 13.5 & 28.6 & & & \\
\hline 3 & 108 & 13.5 & 28.4 & 38.5 & & \\
\hline 4 & 23 & 14.5 & 26.1 & 35.5 & 42.8 & \\
\hline 5 & 3 & 13.8 & 23.6 & 32.3 & 41.1 & 48,6 \\
\hline \multicolumn{2}{|c|}{ Average length, cm } & $\mathbf{1 3 , 5 2}$ & $\mathbf{2 8 . 1 2}$ & $\mathbf{3 7 . 8 7}$ & $\mathbf{4 2 . 6 5}$ & $\mathbf{4 8 . 5 6}$ \\
\hline $\begin{array}{c}\text { Average annual growth, } \\
\text { cm }\end{array}$ & $\mathbf{1 3 , 5 2}$ & $\mathbf{1 4 . 6 0}$ & $\mathbf{9 . 7 5}$ & $\mathbf{4 . 7 8}$ & $\mathbf{5 . 9 1}$ \\
\hline
\end{tabular}

In the first year of life of fish of the species, gonads developed slowly. In spring, all yearling fish of both sexes had gonads at maturity stage I, they had a mass of several mg and looked like colorless brownish, translucent filaments. It is difficult to visually divide fish by sex. On histological sections of the gonads, nests of oogonia and several oocytes of the beginning of small growth were visible.

In spring, all 2-year-old females had gonads at maturity stage II. The gonads widened slightly, became thickened. The gonads are easily differentiated by sex. The ovaries are translucent (their weight was $1.1-12.1 \mathrm{~g}$ ), the testes are milky white. A significant number of small oocytes appeared in the ovaries. In the testes, the edges of the gonads, when cut, remain sharp, not melted.

Variability of maturation of 3-year-old females in spring was noted: gonads in larger fish of this age (TL more than $27 \mathrm{~cm}$ ) reached stage IV, maturing eggs had a diameter of 0.61-1.39 mm; they were filled with yolk and were clearly visible with the naked eye. Numerous oocytes at the stage of vitellogenesis were present on histological sections of females. But there were some 3-year-old female European bream with gonads still at maturity stage II (they had a total body length of less than $30 \mathrm{~cm}$ ).

In spring, all 3-year-old males were mature and had gonads at stage IV of maturity. In spring, all 4-year-old females and males were sexually mature and had gonads at stage IV of maturity.

Thus, the achievement of the first maturity of European bream in the Tudakul reservoir occurs at the age of 3-4 years, when males and females reach $34-36 \mathrm{~cm}$ in total length (30$32 \mathrm{~cm}$ in standard length).

\subsection{Amur white bream}

In total, a sample was collected from 83 individuals of the Amur white bream, including 41 females and 42 males. There were no significant differences between sex lengths, so all calculations were performed in the combined group (males + females). The age of fish in 
the sample varied from 1 to 6 years, total body length from 24 to $54.1 \mathrm{~cm}$, standard length from 18 to $46.6 \mathrm{~cm}$, and total body weight from 105 to $2,163 \mathrm{~g}$.

The scales of the Amur bream are cycloidal. The species belongs to large-scale fish. In colder months, sclerites on scales are located close to each other; in warmer months, sclerites are located farther apart (widely spaced). Annual rings can be morphologically determined by belts of sclerites closely spaced to each other. Annual rings on the scales of immature white Amur bream are laid in March, in sexually mature fish - in May.

The relationship between total length and body weight is shown in Figure 2 and can be characterized by the regression equation: $\mathrm{W}=0.005 * \mathrm{TL}^{3.201}(\mathrm{r}=0.96)$. The relationship between standard body length and total body length can be described by the equation TL $=$ $1.107 * \mathrm{SL}+2.308(\mathrm{r}=0.99)$.

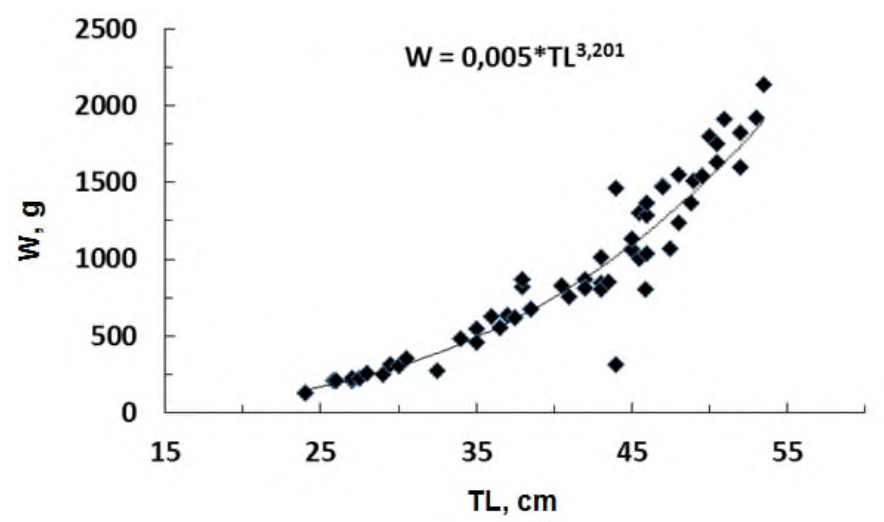

Fig. 2. Dependence of total body weight on total body length in Amur white bream in the Tudakul reservoir, Uzbekistan

The reverse calculation of the Amur bream growth is shown in Table 3. R. Lee's phenomenon also did not appear.

Table 3. Reconstructed growth rate of white Amur bream in the Tudakul reservoir (above the line spread, below the line - average)

\begin{tabular}{|c|c|c|c|c|c|c|c|}
\hline \multirow{2}{*}{$\begin{array}{c}\text { Age group, } \\
\text { year }\end{array}$} & \multirow{2}{*}{ \# } & \multicolumn{6}{|c|}{ TL, $\mathbf{c m}$} \\
\hline & & $T L_{1}$ & $T L_{2}$ & $T L_{3}$ & $T L_{4}$ & $T L_{5}$ & $T L_{6}$ \\
\hline 1 & 17 & 13.09 & & & & & \\
\hline 2 & 10 & 13.64 & 24.42 & & & & \\
\hline 3 & 7 & 15.29 & 27.94 & 35.09 & & & \\
\hline 4 & 15 & 15.07 & 27.61 & 37.29 & 42.79 & & \\
\hline 5 & 13 & 13.53 & 24.75 & 33.66 & 41.69 & 45.76 & \\
\hline 6 & 3 & 12.65 & 23.32 & 32.78 & 40.48 & 45.98 & 48,62 \\
\hline \multicolumn{2}{|c|}{ Average length, $\mathrm{cm}$} & 13,9 & 25.6 & 34.7 & 41.7 & 45.9 & 48.6 \\
\hline \multicolumn{2}{|c|}{$\begin{array}{c}\text { Average annual growth, } \\
\mathrm{cm}\end{array}$} & 13,9 & 11.7 & 9.1 & 7.0 & 4.2 & 2.7 \\
\hline
\end{tabular}

In the first year of fish life, the gonads developed slowly. In spring, all yearling fish of both sexes had gonads at stage I.

In spring, it was morphologically easy to determine the sex of the fish in all 2-year-old fish by biological analysis. The females had stage II gonads. In autumn, three-year-old $(2+)$ females had ovaries at stage III. 
In the spring, all 3-year-old females reached first maturity and had ovaries at maturity stage IV.

In 2-year-old males, variability in the maturation rate was revealed: in the spring, the gonads of larger fish (with a total body length of more than $34 \mathrm{~cm}$ ) reached stage IV, but most of the 2-year-old males still had stage II gonads.

In spring, all 3-year-old males were sexually mature and had gonads at stage IV).

Thus, under the conditions of the Tudakul reservoir, the white Amur bream is characterized by normal sexual maturity, the first maturity of the fish of both sexes reaches the age of 3 years, when males and females reach a total length of $34-36 \mathrm{~cm}$.

\section{Discussion and conclusion}

European bream can expand its distribution due to its ecological plasticity and high resistance to adverse environmental conditions. Growth and reproduction, which were usually cited as the main factor in the success of a species invasion, could be the reason for the creation of new populations. European bream took root in the conditions of Uzbekistan, in many lentic water bodies of the plain zone the populations became large, bream entered the list of commercial fish, incl. - since the 1990s, European bream has been constantly present in catches in the Zarafshan basin. In 2003-2018, the annual catch of European bream in the Tudakul reservoir was 68.8 - 400 t/year. European bream is a popular recreational fishing target.

European bream was one of the first fish species for which age estimation methods were applied. A calcified structure such as scale was used [13]. It was determined that the annual zone at scale includes zones of congested and spaced sclerites, and the rings are visible as a zone of sclerites. Researchers have substantiated the use of a modification of the direct proportional Fraser-Lee method [13-15].

Fish growth studies, including growth reversal data, are important tools in fisheries research and management that are used to determine age and height from recording (calcined) structures. Growth and maturation data provide ichthyologists with an important basis for fishery management and data on the characteristics of fish populations in specific water bodies $[5,9]$. The growth of fish can be influenced by factors such as annual water temperature, fish population density, food availability and quality. [7]. Our data show that in the Tudakul reservoir, the growth of European bream is the fastest in the first 3 years; in the subsequent years of life, the growth rate slowed down due to reaching maturity.

In Uzbekistan, European bream reaches its first maturation at the age of 3 years in different water bodies $[8,13]$. Our data are in good agreement with these data (Table 4). At the same time, the bream of the Tudakul reservoir has one of the highest growth rates in Uzbekistan.

The introduction of Chinese herbivorous cyprinids into the reservoirs of Uzbekistan was carried out in the early 1960s. In total, 47 fish species were introduced into the water bodies of Uzbekistan, including 23 target species and 24 random ones [13, 14]. At that time, Amur white bream (also a representative of the fish fauna of China) was not seen in Uzbekistan. But in the 2000s, this species was first recorded in the network of the Amu-Bukhara machine channel, which takes water from the middle reaches of the Amu Darya River and transports it to the lower reaches of the Zarafshan River in Uzbekistan. Apparently, individuals of the Amur bream accidentally ended up in those lots of Chinese fish that were brought to fish farms in neighboring Turkmenistan (which also belonged to the Amu Darya river basin). The species took root and naturalized in Turkmenistan, penetrated into the Amu Darya, and in the 2000s - into Uzbekistan. 
Table 4. Growth of European bream in different regions of its range (TL - total body length, SL - standard body length)

\begin{tabular}{|c|c|c|c|c|c|c|c|c|c|c|c|}
\hline \multirow{2}{*}{ Reservoir } & \multirow{2}{*}{ Length } & \multicolumn{9}{|c|}{ Length along with age, cm (stages) } & \multirow{2}{*}{ Auhtor } \\
\hline & & $\mathbf{I}$ & II & III & IV & $\mathbf{V}$ & VI & VII & VIII & IX & \\
\hline $\begin{array}{l}\text { Dombi } \\
\text { Lake }\end{array}$ & TL & 6.4 & 11.8 & 16.9 & 21.4 & 25.4 & 29.1 & 32.4 & 35 & 37.6 & $\begin{array}{c}\text { Zalachowsli, } \\
\text { Wieski, } 2018 \text { [13] }\end{array}$ \\
\hline $\begin{array}{l}\text { Danube } \\
\text { River }\end{array}$ & TL & 8.1 & 13.3 & 17.6 & 21.2 & 24 & 26.4 & 28.5 & 30.5 & 32.4 & $\begin{array}{c}\text { Treer et al., } 2013 \\
{[10]}\end{array}$ \\
\hline $\begin{array}{l}\text { Balaton } \\
\text { Lake }\end{array}$ & SL & 7.2 & 11.4 & 14.9 & 17.8 & 22.1 & 24.2 & 25.9 & 27.6 & 28.8 & $\begin{array}{c}\text { Dauba, Biro, } 2012 \\
{[8]}\end{array}$ \\
\hline $\begin{array}{l}\text { Balkhash } \\
\text { Lake }\end{array}$ & SL & - & 11.1 & 15.3 & 18.7 & 21.6 & 24.5 & 26 & 28 & 30 & Fish ..., 2008 [5] \\
\hline $\begin{array}{l}\text { Chardara } \\
\text { reservoir }\end{array}$ & SL & - & 17.4 & 22.5 & 27.1 & 30.8 & 34.4 & 37.7 & 39.8 & 41.4 & Fish ..., 2008 [5] \\
\hline $\begin{array}{c}\text { Kapchagay } \\
\text { reservoir }\end{array}$ & SL & - & 16.0 & 22.8 & 25.9 & 27.5 & 29.5 & 31.2 & 33.2 & 34.5 & Fish ..., 2008 [5] \\
\hline \multirow{2}{*}{$\begin{array}{l}\text { Tudakul } \\
\text { reservoir }\end{array}$} & $\mathrm{SL}$ & 10.5 & 22.7 & 30.9 & 34.9 & 39.8 & & & & & \multirow{2}{*}{ This study } \\
\hline & TL & 13.5 & 28.1 & 37.9 & 42.7 & 48.6 & & & & & \\
\hline
\end{tabular}

Recently, specimens of white Amur bream under the age of 6 years have regularly been caught in the catches in the Tudakul reservoir. The species has a fairly rapid growth, reaches large sizes and has entered commercial catches over the past few years. Basically, fish of both sexes mature for the first time at the age of 3 years. It can be concluded that in the Amu Darya, and maybe already in the Tudakul reservoir, a broodstock of this species has formed, and natural reproduction is underway.

The biology of bream is poorly understood; we were unable to find data in the literature for comparison with data on the Tudakul reservoir.

\section{References}

1. A. A. Amanov, Ecology of fish in water bodies in the south of Uzbekistan and neighboring republics, 161 (FAN Press, Tashkent, 2005)

2. J. Brodersen, J. H. Hansen, C. Skov, Ecology of Freshwater Fish 28(4), 650-660 (2019)

3. A. P. Makeeva, Fish embryology, 216 (MSU Press, Moscow, 2012)

4. D. Tenji, B. Micic, S. Sipos, B. Miljanovic, I. Teodorovic, S. Kaisarevic, Environmental Sciences Europe 32(1), 1-15 (2020)

5. Fish of Kazakhstan, 304 (Nauka Press, Alma-Ata, 2008)

6. T. V. Salikhov, B. G. kamilov, A. K. Atadjanov, Fish of Uzbekistan, 152 (Chinor ENK Press, Tashkent, 2001)

7. S. Blanchet, G. Loot, G. Grenouillet, E. Bross, Ecol. Freshwater Fish 16, 133-143 (2007)

8. F. Dauba, P. Biro, Hydrobiol 77(2), 225-235 (2012)

9. E. García-Berthou, Journal of Fish Biology 71, 33-35 (2007)

10. T. Treer, A. Opačak, I. Aničic, R. Safner, M. Piria, T. Odak, Czech Journal of Animal Sciences 48, 251-256 (2013)

11. R. Yonekura, Y. Kohmatsu, M. Yuma, Biol. J. the Linnean Soci. 9, 601-610 (2007)

12. M. A. Yuldashov, International Journal of Science and Research 1, 1213-1219 (2018)

13. W. Zalachowsli, K. Wieski, Electronic Journal of Polish agricultural universities 1, 3 (2018) 
14. J. K. H. Zimmerman, B. Vondracek, Canadian J Fish. and Aquatic Sci. 63, 1526-1535 (2006)

15. M. Chunchukova, D. Kirin, D. Kuzmanova, S. Shukerova, Scientific Papers-Series DAnimal Science 60, 327-332 (2017)

16. R. Kulmatov, A. Taylakov, S. Khasanov, Environmental Science and Pollution Research, 1-11 (2021) 